\title{
Atividade antimicrobiana de Struthanthus vulgaris (erva-de-passarinho)
}

\author{
O.M.C. Vieira*, M.H. Santos, G.A. Silva, A.M. Siqueira \\ Departamento de Farmácia, Escola de Farmácia e Odontologia de Alfenas, Centro Universitário \\ Federal, Rua Gabriel Monteiro da Silva 714, 37130-000, Alfenas, MG, Brasil
}

\begin{abstract}
RESUMO: As plantas do gênero Struthanthus são conhecidas como ervas-de-passarinho e parasitam pomares no Brasil, principalmente os de laranjeiras e goiabeiras. Na medicina popular são usadas nas afecções das vias respiratórias. O extrato hidroetanólico a $70 \%$ de folhas frescas de Struthanthus vulgaris apresentou atividade antimicrobiana contra amostras bacterianas Gram positiva e Gram negativa. Este extrato não apresentou, nas condições testadas, atividade contra fungos. As amostras bacterianas mais sensíveis ao extrato foram Bacillus cereus (ATCC 11778), Micrococcus luteus (ATCC 9341), Staphylococcus aureus (ATCC 6538), S. epidermidis (ATCC 12228) e P. aeruginosa (ATCC 27853), usando o método de difusão em agar. As frações obtidas, pela partição líquido-líquido do extrato hidroetanólico a 70\%, com solventes de polaridades crescentes (clorofórmio, acetato de etila, n-butanol e água), apresentaram diferentes atividades inibitórias. A fração que apresentou a maior atividade contra bactéria Gram positiva (B. cereus) e Gram negativa ( $P$. aeruginosa) foi aquela obtida com n-butanol. Nessa fração foram detectados flavonóides, taninos condensados (proantocianidinas) e saponinas.
\end{abstract}

Unitermos: Struthanthus vulgaris, erva-de-passarinho, proantocianidinas, atividade antimicrobiana.

\begin{abstract}
Antimicrobial activity of Struthantus vulgaris (erva-de-passarinho)". Struthantus vulgaris (mistletoe) is one of the most common hemiparasite species in Brazil. It occurs as a parasite of orchards, mainly in orange and guava trees. Some authors mention Struthantus use in traditional medicine for respiratory diseases treatment. Fresh leaves concentrated hydroalcoholic extract showed antimicrobial activity against Gram positive and Gram negative bacterial samples. In tested conditions, these extracts did not show activity against fungi. The more susceptible bacterial samples to fresh leaves hydroalcoholic extract were Bacillus cereus (ATCC 11778), Micrococcus luteus (ATCC 9341), Staphylococcus aureus (ATCC 6538), S. epidermidis (ATCC 12228) and Pseudomonas aeruginosa (ATCC 27853). The method used for assessment of antimicrobial activity was agar diffusion. Fractions obtained from fresh leaves concentrated alcoholic extracts with increasing polarity solvents (chloroform, ethyl acetate, n-butanol and water) showed different inhibitory activities. n-Butanol fraction showed greater activity against Gram positive bacteria $(B$. cereus) and Gram negative bacteria (P. aeruginosa). In this fraction, flavonoids, condensed tannins (proanthocyanidins) and saponins, were found.
\end{abstract}

Keywords: Struhtanthus vulgaris, mistletoe, proanthocyanidins, antimicrobial activity.

\section{INTRODUÇÃO}

As plantas pertencentes à família Loranthaceae têm sido, há muito tempo, reconhecidas como portadoras de propriedades terapêuticas. Esta família é composta de 40 gêneros e 1500 espécies, distribuídas em regiões tropicais e subtropicais de ambos os hemisférios, revelando-se pouco freqüentes nas regiões temperadas (Venturelli, 1981). No campo da medicina, em diferentes países, espécies do gênero Struthanthus são usadas para tratamento de várias enfermidades, como por exemplo, na Nicarágua, a S. cassythoide é indicada para dor em geral, febre, desordens respiratórias e pulmonares, erupções e feridas na pele (Coe; Anderson, 1996). Segundo Almeida (1993), a espécie S. flexicaulis, originária do Brasil e
America Tropical, possui atividades medicinais como energético e também contra leucorréia, bronquite e tumores diversos.

A espécie $S$. vulgaris é um dos hemiparasitas mais comuns de árvores ornamentais e plantas frutíferas (Corrêa, 1969). No Brasil, é planta própria das regiões de mata pluvial, apreciando temperaturas amenas, razão pela qual é igualmente muito comum no sul do país e nas serras do leste (Rizzini, 1968). Segundo Salatino et al. (1993), contém relativamente altas concentrações de taninos condensados. Nas folhas, estes taninos são mais comuns em parênquima paliçadico e nervura central das folhas. 


\section{MATERIAL E MÉTODOS}

\section{Coleta e identificação do material vegetal}

As folhas e os caules de S. vulgaris (Mart.) (erva-de-passarinho) foram coletados em março de 2001, na propriedade rural, denominada Fazenda Nossa Senhora Aparecida, no município de Alfenas-MG entre as coordenadas $21^{\circ} 26^{\prime}$ '260's e $45^{\circ} 57^{\prime}$ ' $943^{\prime \prime} \mathrm{W}$, com altitude de 815 metros. A identificação da espécie foi realizada pela pesquisadora Marie Sugiyama do Instituto de Botânica da Universidade de São Paulo. Uma exsicata encontra-se depositada, com o número 00187, no Herbário Escola de Farmácia e Odontologia de Alfenas (HEFOA), na Escola de Farmácia e Odontologia de Alfenas/Centro Universitário Federal.

Obtenção do extrato hidroetanólico a $70 \%$ e das frações $F_{1}$ a $F_{4}$

O extrato hidroetanólico a $70 \%$ de folhas (500 g) foi obtido por maceração $(20 \%$ p/v) por seis dias. Após este período, o extrato foi filtrado em papel de filtro comum, obtendo-se $2200 \mathrm{~mL}$ e concentrado em evaporador rotatório sob pressão reduzida, até que aparentemente todo o álcool fosse eliminado, reduzindo para aproximadamente $600 \mathrm{~mL}$. Em seguida o extrato foi concentrado em liofilizador a $-70{ }^{\circ} \mathrm{C}$, obtendo-se o volume de $109 \mathrm{~mL}$. Este passou a ser denominado extrato hidroetanólico concentrado (EHC), que, posteriormente, foi congelado. A metade do volume do extrato concentrado (54,5 mL), após descongelamento, foi centrifugada a 5000 rpm por 5 minutos, para a retirada de uma substância de aspecto viscoso. O sobrenadante do extrato hidro etanólico concentrado (SEHC) foi utilizado para determinação das possíveis atividades antibacteriana e antifúngica.

Uma alíquota de $25 \mathrm{~mL}$ do EHC de $S$. vulgaris, foi também descongelada e submetida à técnica de partição líquido-líquido com clorofórmio (10 extrações consecutivas de $60 \mathrm{~mL}$ cada), acetato de etila (5 extrações de $60 \mathrm{~mL}$ ) e n-butanol (9 extrações de $60 \mathrm{~mL}$ ). O critério adotado para definir o número de extrações com cada solvente, foi a ausência de coloração no líquido extrator. As frações obtidas foram concentradas em evaporador rotatório sob pressão reduzida, e até a secura em banhomaria $\left(55^{\circ} \mathrm{C}\right)$, e denominadas, $\mathrm{F}_{1} \mathrm{~F}_{2}, \mathrm{~F}_{3}$, respectivamente. A fração restante, denominada $F 4$, após concentração em evaporador rotatório foi liofilizada.

\section{Determinação da atividade antimicrobiana}

O sobrenadante do extrato hidroetanólico concentrado (SEHC), foi esterilizado por filtração em membrana esterilizante Millex ${ }^{\circledR}$, poro $0,22 \mu \mathrm{m}$, e submetido a testes de atividade antimicrobiana frente às bactérias Bacillus cereus (ATCC 11778), B. subtilis
(ATCC 6633), Escherichia coli (ATCC 8739), Klebisiella pneumoniae (ATCC 13883) Micrococcus luteus (ATCC 9341), Salmonella typhimurium (ATCC 14028), Staphylococcus aureus (ATCC 6538), S. epidermidis (ATCC 12228), Pseudomonas aeruginosa (ATCC 25619), P. aeruginosa (ATCC 27853) e as leveduras Candida albicans (ATCC 10231) e Saccharomyces cerevisiae (ATCC 2601).

As frações $\mathrm{F}_{1}, \mathrm{~F}_{2}, \mathrm{~F}_{3}$ e $\mathrm{F}_{4}$ foram emulsionadas em solução de Tween 80 a 2\% e esterilizadas (Millex®). As mesmas foram submetidas à testes de atividade antimicrobiana frente a duas amostras bacterianas, $B$. cereus (ATCC 11778), Gram positiva e P. aeruginosa (ATCC 27853), Gram negativa.

Para as provas de avaliação antimicrobiana do SEHC e das frações $F_{1}, F_{2}, F_{3}$ e $F_{4}$ utilizaram-se placas de Petri de $9 \mathrm{~cm}$ de diâmetro, contendo $20 \mathrm{~mL}$ de ágar Mueller-Hinton (Difco), para bactérias e $20 \mathrm{~mL}$ de ágar Sabouraud (Difco) para leveduras.

Com auxílio de um furador de rolhas, estéril, foram feitos orifícios de $7 \mathrm{~mm}$ de diâmetro no gel, para receberem os extratos, as frações e as soluções controle.

Na avaliação da atividade antimicrobiana do SEHC, utilizou-se suspensões de cada microrganismo feitas em solução fisiológica correspondendo ao tubo $\mathrm{n}^{\mathrm{o}} 1$ da escala MacFarland. Neste ensaio, usou-se $50 \mu \mathrm{L}$ do extrato e $50 \mu \mathrm{L}$ de solução controle estéril (solução aquosa).

$\mathrm{Na}$ avaliação da atividade antibacteriana das frações $\mathrm{F}_{1}$ a $\mathrm{F}_{4}$ utilizou-se suspensões de microrganismo em solução estéril correspondentes a $90 \%$ e $95 \%$ de transmitância, leitura espectofotométrica em comprimento de onda de $520 \mathrm{~nm}$. As suspensões de cada microrganismo foram inoculadas nas respectivas placas de Petri contendo meio de cultura, através da técnica de sementeira em superfície utilizando “swab” estéril. As placas de Petri, onde foram inoculadas separadamente as suspensões de microrganismo, correspondente a $90 \%$ de transmitância para $B$. cereus e para $P$. aeruginosa, receberam em cada orifício, alíquotas de $50 \mu \mathrm{L}$ e 100 $\mu \mathrm{L}$ das amostras esterilizadas, preparadas com as frações $\mathrm{F}_{1}, \mathrm{~F}_{2}, \mathrm{~F}_{3}$ e $\mathrm{F}_{4}$ na proporção de $40 \mathrm{mg} / \mathrm{mL}$ em Tween 80 a $2 \%$.. As placas de Petri, onde foram inoculadas as suspensões de microrganismo, correspondentes a $90 \%$ de transmitância para $B$. cereus e para $P$. aeruginosa, receberam em cada orifício $100 \mu \mathrm{L}$ das referidas amostras. Nestes ensaios, foram utilizados para controle, $100 \mu \mathrm{L}$ de uma solução de Tween 80 a $2 \%$ e $100 \mu \mathrm{L}$ de uma solução preparada com $40 \mathrm{mg}$ de n-butanol em $1 \mathrm{~mL}$ de Tween a 2\%, ambas estéreis. Estas placas receberam também, em um dos orifícios, $100 \mu \mathrm{L}$ de amostra, preparada com 40 $\mathrm{mg}$ do EHC com $1 \mathrm{~mL}$ de Tween 80 a 2\%. A esterilização de todas as amostras foi feita através de filtração em membranas esterilizantes Millex ${ }^{\circledR}$ poro 0,22 $\mu \mathrm{m}$.

As placas foram incubadas em estufa a $37{ }^{\circ} \mathrm{C}$ por 24 horas, para bactérias, e à temperatura ambiente por 48 horas, para fungos. Após este período, o diâmetro 
da zona de inibição foi mensurado com o auxílio de régua milimetrada. Considerou-se, no resultado, a diferença entre o diâmetro total da inibição e o diâmetro do orifício (7 mm).

O teste de difusão em ágar para determinação da atividade antimicrobiana foi realizado com base nas recomendações do NCCLS (1997).

\section{Caracterização fitoquímica}

As folhas foram secas em estufa com circulação de ar aquecido à $45^{\circ} \mathrm{C}$, por cerca de 48 horas. Após a secagem, o material foi triturado em moinho manual e, submetido a reações para caracterização de alcalóides, antraquinônicos, livres e combinados, cumarinas e flavonóides (Costa, 1982). Para investigação de óleo essencial utilizou-se cromatografia em camada delgada do destilado de $1 \mathrm{~g}$ do material vegetal (Wagne, Bladt, 1984). Para pesquisa de taninos utilizaram-se reações de precipitação com gelatina e cafeína e para investigação de saponinas foi observado a ocorrência de espuma persistente do extrato aquoso (Alice et al., 1995).

No extrato hidroetanólico foram investigadas as presenças de flavonóides, taninos e saponinas, seguindo as mesmas metodologias relatadas anteriormente.

As frações foram submetidas à teste para flavonóides (Costa, 1982), para proantocianidinas
(Santos, Mello In: Simões, 2002) e para saponinas (Alice et al., 1995).

\section{Caracterização espectroscópica}

As frações do extrato hidroetanólico com os solventes acetato de etila $\left(\mathrm{F}_{2}\right)$, n-butanol $\left(\mathrm{F}_{3}\right)$ e água $\left(F_{4}\right)$, foram submetidas às técnicas espectroscópicas, no ultravioleta (Espectrofotômetro Shimadzu, UV-visível 1601PC), usando os aditivos cloreto de alumínio/ ácido clorídrico, acetato de sódio/ácido bórico e no infravermelho (Espectrômetro Shimadzu IR-408, em pastilhas de $\mathrm{KBr}$ ).

\section{RESULTADOS}

A tabela 1 mostra os resultados, obtidos com a utilização do sobrenadante do extrato hidroetanólico de $S$. vulgaris, frente a 10 amostras bacterianas e 2 fúngicas. $\mathrm{O}$ extrato não recebeu ajuste de $\mathrm{pH}$, que apresentou valores entre 5,3 - 5,5.

A tabela 2 mostra os resultados obtidos com as frações $\mathrm{F}_{1}, \mathrm{~F}_{2}, \mathrm{~F}_{3}$ e $\mathrm{F}_{4}$, obtidas pela partição líquidolíquido do extrato hidroetanólico concentrado (EHC) de S. vulgaris.

$\mathrm{Na}$ folha foram identificados os seguintes grupos químicos: flavonóides, taninos e saponinas. No extrato

Tabela 1. Medida do halo de inibição do sobrenadante do extrato hidroetanólico concentrado (SEHC) de folhas frescas de $S$. vulgaris, frente a algumas amostras bacterianas e fúngicas.

\begin{tabular}{|c|c|c|}
\hline \multirow[t]{2}{*}{ Microrganismos } & \multicolumn{2}{|c|}{ Diâmetro do halo de inibição (mm) } \\
\hline & *SEHC (pH 5,5) & $\mathrm{C}(\mathrm{pH} \quad 6,1)$ \\
\hline B. cereus ATCC 11778 & 21 & 0 \\
\hline B. subtilis ATCC 6633 & 17 & 0 \\
\hline E. coli ATCC 8739 & 8 & 0 \\
\hline K. pneumoniae $\quad$ ATCC 13883 & 18 & 0 \\
\hline M. luteus ATCC 9341 & 28 & 0 \\
\hline S. typhimurium ATCC 14028 & 16 & 0 \\
\hline S. aureus ATCC 6538 & 27 & 0 \\
\hline S. epidermidis ATCC 12228 & 28 & 0 \\
\hline P. aeruginosa ATCC 25619 & 18 & 0 \\
\hline P. aeruginosa ATCC 27853 & 28 & 0 \\
\hline C. albicans ATCC 10231 & 0 & 0 \\
\hline S. cervisiae ATCC 2601 & 0 & 0 \\
\hline
\end{tabular}

*SEHC: Sobrenadante do extrato hidroetanólico concentrado (180 mg/mL). Volume da amostra: 50 L.; C: Controle.

\begin{tabular}{r|c}
\hline Rev. Bras. Farmacogn. & 151 \\
Braz J. Pharmacogn. & 151 15(2):abr/jun. 2005
\end{tabular}


Tabela 2. Medida do halo de inibição de bactérias obtida pelo extrato hidroetanólico concentrado (EHC) de folhas frescas e suas frações de $S$. vulgaris, pela técnica de extração líquido/líquido com solventes de polaridades crescentes.

\begin{tabular}{|c|c|c|c|c|c|c|c|c|c|}
\hline \multirow[t]{2}{*}{ Bactérias } & \multirow{2}{*}{$\begin{array}{c}\text { Transmitância } \\
\text { \% }\end{array}$} & \multirow{2}{*}{$\begin{array}{l}\text { *Volume das } \\
\text { amostras }(\mu \mathrm{L})\end{array}$} & \multicolumn{3}{|c|}{ Diâmetro do halo } & \multicolumn{3}{|c|}{ de inibição (mm) } & \multirow[b]{2}{*}{$\mathrm{Bt}$} \\
\hline & & & $\mathrm{EHC}$ & $F_{1}$ & F 2 & F 3 & $\mathrm{~F} 4$ & Tw & \\
\hline B. cereus & 90 & 50 & 0 & 0 & 0 & 4 & 0 & - & - \\
\hline \multirow[t]{2}{*}{ (ATCC 11778) } & & 100 & 0 & 0 & 0 & 7 & 0 & 0 & 0 \\
\hline & 95 & 100 & 2 & 0 & 5 & 8 & 6 & 0 & 0 \\
\hline P. aeruginosa & 90 & 50 & 0 & 0 & 0 & 0 & 0 & - & - \\
\hline \multirow[t]{2}{*}{ (ATCC 27853) } & & 100 & 0 & 0 & 0 & 0 & 0 & 0 & 0 \\
\hline & 95 & 100 & 4 & 0 & 0 & 6 & 5 & 0 & 0 \\
\hline
\end{tabular}

EHC - Extrato hidroetanólico concentrado; $F_{1}$ - Fração clorofórmica; $F_{2}$ - Fração em acetato de etila; $F_{3}$ - Fração butanólica; $F_{4}$ - Fração aquosa; Tw - Tween 80 a 2\%; Bt - n-butanol.

Amostras na concentração de 4 × $10^{4} \mu \mathrm{g} / \mathrm{mL}$, em Tween 80 a $2 \%$.

hidroetanólico concentrado (EHC) foram pesquisadas e detectadas as presenças de flavonóides, taninos e saponinas. Nas frações $F_{2}, F_{3}$ e $F_{4}$, foram constatadas as presenças de flavonóides, proantocianidina e saponinas, mas em quantidades aparentemente diferentes.

A tabela 3 expressa os resultados obtidos na identificação dos grupos químicos presentes nas frações $\mathrm{F}_{2}, \mathrm{~F}_{3}$ e $\mathrm{F}_{4}$ de $S$. vulgaris, com as diferentes intensidades de coloração, em se tratando de flavonóides e proantocianidinas (taninos condensados), e capacidade de promover a formação de espuma persistente, no que se refere a saponinas.

No espectro de absorção no ultravioleta com a fração $F_{2}$, usando solução 0,04 mg/mL em metanol foram observados dois máximos de absorção: um ocorrendo em $280 \mathrm{~nm}$ e outro em $363 \mathrm{~nm}$.
Com a adição de cloreto de alumínio e nova leitura, ocorreu um deslocamento da curva de absorção que não foi regenerado com a adição subseqüente de ácido clorídrico (10\% em metanol). Em uma outra porção da mesma solução em metanol, após a adição de acetato de sódio, foi observado no espectro de absorção um novo deslocamento da curva original que não foi regenerado com a adição subseqüente de ácido bórico.

A fração $F_{3}$, dissolvida na mesma proporção $(0,04 \mathrm{mg} / \mathrm{mL})$ em metanol, quando submetida à análise espectrôfotométrica no UV-visível, apresentou espectro com um máximo de absorção em 255 nm. Após adição de cloreto de alumínio houve deslocamento da curva, o qual foi regenerada com a adição de ácido clorídrico. Em nova porção desta solução, após adição de acetato de sódio e nova leitura no espectrofotômetro-UV, foi observado

Tabela 3. Grupos químicos presentes nas frações $\mathrm{F}_{2}, \mathrm{~F}_{3}$ e $\mathrm{F}_{4}$ de $S$. vulgaris indicando as diferentes intensidades das reações.

\begin{tabular}{lccc}
\hline \multicolumn{2}{c}{ Frações $(100 \mathrm{mg})$} & Grupos químicos & Saponinas \\
\cline { 2 - 4 } & Flavonóides & Proantocianidinas & Negativo \\
F2 & +++ & + & +++ \\
F4 & + & +++ & +++ \\
\hline
\end{tabular}

(+++)- Forte intensidade; (++)- Média intensidade; (+)- Baixa intensidade. 
deslocamento da curva a qual não foi regenerada com a adição de ácido bórico.

A fração $F_{4}$, dissolvida em metanol na mesma proporção já relatada, quando analisada pela espectrofotometria na região UV-visível apresentou máximo de absorção em 265 nm. Após adição de cloreto de alumínio houve deslocamento da curva que foi praticamente regenerada com adição de ácido clorídrico.

Uma nova porção desta solução $\left(\mathrm{F}_{4}\right)$, quando adicionada de acetato de sódio, apresentou deslocamento batocrômico da curva no espectro, o qual não foi regenerado com ácido bórico.

$O$ espectro na região do infravermelho da fração, obtida no fracionamento com acetato de etila $\left(\mathrm{F}_{2}\right)$, apresentou bandas de absorção em torno de 1620, 1510 e $1430 \mathrm{~cm}^{-1}$. O espectro na região do infravermelho da fração obtida com n-butanol $\left(\mathrm{F}_{3}\right)$, apresentou bandas de absorção em 1610, 1500 e 1440 cm$^{-1}$ e o mesmo espectro da fração, obtida da fração aquosa $\left(\mathrm{F}_{4}\right)$, apresentou banda de absorção em $1620 \mathrm{~cm}^{-1}$.

Os espectros, obtidos na região do infravermelho de todas as frações apresentaram também bandas de absorção entre $3500-3200 \mathrm{~cm}^{-1}$.

\section{DISCUSSÃO}

Na investigação da possível ação antimicrobiana da espécie $S$. vulgaris, pode-se evidenciar a inibição do crescimento das amostras bacterianas pelo extrato hidroetanólico. Esse extrato inibiu algumas amostras de bactérias Gram positivas e Gram negativas. O extrato não inibiu, nas condições testadas, o crescimento das leveduras C. albicans e S. cerevisiae. A fração que forneceu maior halo de inibição, tanto para bactéria Gram positiva como para Gram negativa, foi a $F_{3}$, na qual foi evidenciada a presença de flavonóides, proantocianidinas e saponinas. Esta fração inibiu a amostra Gram negativa somente quando foi aumentada a concentração da emulsão e diminuída a concentração da suspensão de bactérias.

Foram detectados flavonóides, taninos e saponinas nas folhas e no extrato hidroetanólico concentrado (EHC).

Nas frações $F_{2}, F_{3}$ e $F_{4}$, as seguintes bandas de absorção no ultravioleta foram observadas: $F_{2}=380-363$ $\mathrm{nm} ; \mathrm{F}_{3}=255 \mathrm{~nm} ; \mathrm{F}_{4}=265$. Os flavonóides apresentam no ultravioleta 2 máximos de absorção, um entre 240-285 nm e outro entre 300-400 nm (Zuanazzi; Montanha, 1970).

Com o uso de aditivos $\left(\mathrm{AlCl}_{3}, \mathrm{NaOAc} \mathrm{e} \mathrm{H}_{3} \mathrm{BO}_{3}\right)$ foi detectada a presença de hidroxila quelatogênica na fração $F_{2}$ e hidroxilas na posição orto nas frações $F_{2}, F_{3}$ e $\mathrm{F}_{4}$ (Mabry, et al. , 1970).

No espectro no infravermelho de $F_{2}, F_{3}$ e $F_{4}$ foram encontradas as seguintes bandas de absorção: $F_{2}$ $=1620,1510$ e $1430 \mathrm{~cm}^{-1} ; \mathrm{F}_{3}=1610,1500$ e $1440 \mathrm{~cm}^{-1}$; $\mathrm{F}_{4}=1620 \mathrm{~cm}^{-1}$. Bandas fortes, características do esqueleto aromático e de heteroaromático, aparecem na região 1600-1300 cm-1 e bandas de absorção entre 3500-3200 $\mathrm{cm}^{-1}$ indicam a presença de hidroxila (Silverstein et al., 1994).

A presença de flavonóides e proantocianidinas na família Lorantaceae foi descrita por Fernandez et al. (1988). Segundo Marles et al. (2003), as proantocianidinas têm recebido considerável atenção como agentes de proteção na prevenção de infecções do trato urinário e, devido a sua ação antioxidante, na prevenção de doenças cardiovasculares.

De acordo com Zee Cheng (1997), estudos demonstraram algumas ações farmacológicas de algumas Loranthaceae como atividade antihipertensiva, antibacteriana, antiviral, diurética e antihepatotóxica. Relatou também a presença do flavonóide quercetina na espécie Loranthus parasiticus.

Kontiokari et al. (2001), compararam a atividade do suco dos frutos das espécies de Vaccinium (cranberrylingonberry) com a bebida Lactobacillus GG na prevenção de infecção no trato urinário em mulheres. Concluíram que, ingerir regularmente este suco, poderia reduzir a recorrência de infecção, causada pela Escherichia coli, o que não correu com a bebida de lactobacilos. Os frutos da espécie Vaccinium contêm proantocianidinas. Alguns destes compostos possuem propriedades antivirais, antibacterianas, antiaderentes ou antioxidantes. As proantocianidinas inibem a atividade das moléculas de adesão. O bloqueio da adesão fimbrial pelo suco dos frutos de Vaccinium previne a $E$. coli e outras bactérias Gram negativas de colonizar as células uroepteliais. Segundo os autores, a profilaxia e tratamento com antimicrobianos pode resultar no aumento de resistência bacteriana entre bactérias uropatogênicas, e o suco dos frutos de Viccinium seria uma alternativa para a prevenção de infecção no trato urinário, que poderia levar à diminuição no uso de antimicrobianos.

A espécie $S$. vulgaris, usada em nosso experimento, encontrava-se vegetando sobre Psidium guajava (goiabeira). Gnan e Demello (1999), demonstraram que o extrato de folhas da goiabeira era ativo contra alguns microrganismos, principalmente para Sthaphylococcus aureus e que este extrato poderia ser uma importante fonte de novos compostos antimicrobianos e que poderia ser usado na conservação de alimentos e como antibióticos.

Os flavonóides são grupos químicos que também apresentam atividade antimicrobiana e são encontrados freqüentemente nas frutas, em muitas espécies vegetais (Zuanazzi; Montanha, 2003).

Amaro Luis et al. (1997), isolaram e identificaram compostos flavonoídicos da Stevia trifloraide com propriedades antibacterianas.

\section{REFERÊNCIAS}

Alice CB 1995. Plantas medicinais de uso popular: atlas farmacognóstico. Canoas: ULBRA. 
Almeida ER 1993. Plantas medicinais brasileiras: Conhecimentos populares e científicos. São Paulo: Hemus.

Amaro Luis JM, Adrian M, Diaz C 1997. Isolation identification and antimicrobial activity of ombuoside from Stevia triflora. Ann Pharm Fr 55: 262-268.

Coe FG, Anderson GJ 1996. Screening of medicinal plants used by the Garifuna of Eastern Nicaragua for bioactive compounds. J Ethnopharmacol 53: 29-50.

Corrêa MP 1969. Dicionário das plantas úteis do Brasil e das exóticas cultivadas. Rio de Janeiro: Ministério da Agricultura.

Costa AF 1982. Farmacognosia. Lisboa: Fundação Calouste Gulbekian.

Fernández T, Wagner ML, Varela BG, Ricco RA, Alvarez E 1998. Study of an Mistletoe, the hemiparasite Ligaria cuneifolia (R. et P.) Tiegh. (Loranthaceae). $J$ Ethnopharmacol 62: 25-34.

Gnan SO, Demello MT 1999. Inhibition of Staphylococcus aureus by aqueous goiaba extracts. J Ethnopharmacol 68: 103-108.

Kontiokari T, Sundqvist K, Nuutinen M, Pokka T, Koskela M, Uhari M 2001. Randomised trial of cranberrylingonberry juice and Lactobacillus GG drink for the prevention of urinary tract infections in women. Brit Med J 322: 1571-1573.

Mabry TJ, Markham KR, Thomas MB 1970. The sistematic identification of flavonoids. New York: SpringerVerlag.

Marles MAS, Ray H, Gruber MY 2003. New perspectives on proanthocyanidin biochemistry and molecular regulation. Phytochemistry 64:367-383.

National Committee for Clinical Laboratory Standards (NCCLS) 1997. Performance standards of antimicrobial disk susceotility tests. Approved standard M2-A6. National Committee for Clinical Laboratory Standards, Wayne, Pa.

Rizzini CT 1968. Flora ilustrada catarinense. Itajaí: P. Raulino Reitz.

Salatino A, Kraus JE, Salatino MLF 1993. Contents of tannins and their histological localization in young and adult parts of Struthanthus vulgaris Mart. (Loranthaceae). Ann Bot London 72: 409-441.

Santos SC, Mello JCP de 2003. Taninos. In: Simões CMO et al. (org.). Farmacognosia: da planta ao medicamento. 5.ed. Porto Alegre/Florianópolis, UFRGS/EDFSC, p.615-683.

Silverstein RM, Bassler GC, Morril TC 1994. Identificação espectrométrica de compostos orgânicos. 5.ed. Rio de Janeiro: Guanabara-Koogan, 299p.

Venturelli M 1981. Estudos sobre Struthanthus vulgaris Mart. : anatomia do fruto e semente e aspecto de germinação, crescimento e desenvolvimento. Revista Brasileira de Botânica 4: 131-147.

Wagner H, Blad S 1984. Plant drug analysis. A thin layer chromatography atlas. 2.ed. Berlim: SpringerVerlag.

Zee Cheng RKY 1997. Anticancer research on Loranthaceae plants. Drugs of the Future 22: 519-530.

Zuanazzi JAC, Montanha JA 2003. Flavonóides. In: Simões CMMO. et al. (org.). Farmacognosia: da planta ao medicamento. 5.ed. Porto Alegre: UFRGS, p.577614. 